\title{
Effects of extracellular matrix proteins on expansion, proliferation and insulin-producing-cell differentiation of ARIP cells
}

\author{
Gary G. Adams ${ }^{1}$, Yu-Xin Cui $^{2}$ \\ ${ }^{1}$ Insulin Diabetes Experimental Research Group (IDER), Faculty of Medicine and Health Science, University of Nottingham, Clifton \\ Boulevard, Nottingham, NG7 2UH UK; ${ }^{2}$ Department of Physiology, Development and Neuroscience, University of Cambridge, \\ Downing Street, Cambridge, CB2 3EG, UK. \\ Email: Gary.Adams@nottingham.ac.uk
}

Received 17 April 2009; revised 25 April 2009; accepted 30 April 2009.

\section{ABSTRACT}

Regeneration of transplantable pancreatic islet cells has been considered to be a promising alternative therapy for type 1 diabetes. Research has suggested that adult pancreatic stem and progenitor cells can be derived into insulin-producing cells or cultivated islet-like clusters given appropriate stimulating conditions. In this study we explored the effect of selective extracellular matrix (ECM) proteins on the potential of insulin-producing cell differentiation using ARIP cells, an adult rat pancreatic ductal epithelial cell line, as a model in vitro. Quantitative single cell morphology analysis indicated that all the four ECM proteins we have used (type I collagen, laminin, fibronectin and vitronectin) increased the single cell area and diameter of ARIP cells. In addition, serum-free cell cultivation was dependent on cell density and particular components; and serum could be replaced when systematic optimisation could be performed. Surface treated with laminin was shown to be able to enhance overall cell expansion in the presence of defined serum-free medium conditions. Collagen treated surfaces enhanced insulin production in the presence of GLP-1 although the insulin gene expression was however weak accordingly. Our results suggest that selective ECM proteins have effects on single cell morphology, adhesion and proliferation of ARIP cells. These ECM molecules however do not have a potent effect on the insulin-producing cell differentiation potential of ARIP cells even combining with GLP-1.

Keywords: Extracellular Matrix; Proliferation; Differentiation; ARIP Cells; Incretin GLP-1

\section{INTRODUCTION}

The pluripotent cells that develop into pancreatic $\beta$-cells are initially derived from pancreatic ductal epithelium. Ductal cell proliferation is subsequently followed by the budding of endocrine cells but little is known about the intrinsic and extrinsic factors which surround differentiation.

Although a number of studies have been carried out to discover the factors that may be responsible for $\beta$-cell proliferation and differentiation, no conclusive evidence is forthcoming $[2,34,35,40,45]$. Some of the known contributory factors reported to be involved in $\beta$-cell acquisition in vitro, include islet neogenesis- associated protein (INGAP), nicotinamide, retinoic acid, glycogen like-peptide (GLP-1) and the pancreatic regenerating gene (Reg) $[6,8,25,29,30,33,41,43]$.

ARIP cells, an adult rat pancreatic ductal epithelial cell line, are derived from an azaserine induced rat nontumourigenic pancreatic carcinoma [17]. ARIP cells express ductal cell markers and carbonic anhydrase under basal cultivation conditions. GLP-1, a peptide which is originally produced from small intestine, has been demonstrated to induce the insulin-producing cell differentiation of ARIP cells; and this effect may be accompanied by the overexpression of PDX-1, a transcription factor which is crucial for pancreatic embryogenesis and insulin secretion [15]. Thus, it can be speculated that ARIP cell is a useful in vitro model with which to study the mechanism of the insulin-producing cell regeneration/neogenesis mediated by corresponding stimuli. On the other hand, cell-ECM and cell-cell interaction is believed an important cellular process in regulating cellular proliferation and differentiation. Particularly, extracellular matrix (ECM) and soluble factors may be involved in the facilitation or induction of cell differentiation, although the exact signalling pathway is not well known $[17,19,26]$. For instance, a previous study has proved that omitting serum is essential for insulin-producing 
cell differentiation, as medium containing serum is found to decrease insulin production and inhibit cyst development, whilst, a Matrigel ${ }^{\mathrm{TM}}$ overlay procedure is found to be vital to encourage the formation of three-dimensional structure from primarily isolated pancreatic ductal cells [13]. It is suggested that ECM adhesion molecules reorganize cytoskeletal architecture and mediate expression of genes responsible for cell differentiation regulation by binding with specific cell surface integrins, and triggering certain downstream signal transduction, $[9,20]$. Within the pancreas, integrin distribution is distinctive on the surfaces of different pancreatic cell types. Thus, by manipulating the interaction of ECM integrin, it may provide a promising approach to inducing insulin-producing cell differentiation. Laminin is found, for example, to promote $\beta$-cell differentiation during cell cultivation [18].

We hypothesised, therefore, that in the presence of certain serum-free media conditions and ECM proteins, ARIP cells could provide an appropriate model for pancreatic insulin-producing differentiation. Herein, we report the use of ARIP cells to explore the possibility of insulin-producing cell acquisition in vitro. Single cell cytogeometry analysis was carried out to find out whether major ECM proteins are capable of modulating ARIP cell morphology in the first instance. Subsequently, ATP-luciferase based assay was performed to see if cell proliferation is dependent on seeding density and particular serum-free media components, when compared with medium containing foetal calf serum (FCS). Surface coverage of ARIP cells was estimated to determine the potential effect of ECM-protein-coated surfaces in the presence of defined serum-free medium. ARIP cells were eventually encouraged to differentiate into insulin-producing cells given ECM proteins, GLP-1 and serum-free medium conditions.

\section{MATERIALS AND METHOD}

\subsection{Reagents}

All chemical reagents and media components were obtained from Sigma (UK) unless mentioned otherwise.

\subsection{Tissue Culture}

ARIP cells were obtained from ATCC (USA) and maintained in F12K medium supplemented with $10 \%$ FCS, $100 \mu \mathrm{g} / \mathrm{ml}$ streptomycin and $100 \mathrm{units} / \mathrm{ml}$ penicillin at 37 ${ }^{\circ} \mathrm{C}$ in a humidified, 5\% CO2 atmosphere. For experimental use, ARIP cells were passaged from tissue culture flasks using a $0.25 \%$ trypsin $/ 0.02 \%$ EDTA solution. In order to determine the optimal serum-free tissue culture conditions, F12K medium was supplemented with 1 $\mathrm{g} / \mathrm{L}$ ITS supplement (containing $5 \mathrm{mg} / \mathrm{L}$ insulin +5 $\mathrm{mg} / \mathrm{L}$ transferrin $+5 \mathrm{mg} / \mathrm{L}$ selenium), $2 \mathrm{~g} / \mathrm{L}$ BSA, 10 $\mathrm{mM}$ nicotinamide, $10 \mathrm{ng} / \mathrm{ml}$ keratinocyte growth factor
(KGF) and 10nM Glucagon-Like Peptide-1 (GLP-1) together or separately.

\subsection{Surface Coating and Cell Treatment}

Multiwell plates with tissue culture (TC) surface (Nunc, Denmark) were coated with Collagen Type I (CN. Upstate, USA), Fibronectin (FN), Laminin (LN) and Vitronectin (VN) respectively according to product instructions. The concentrations of the four ECM proteins were $0.1 \mu \mathrm{g} / \mathrm{cm}^{2}, 1 \mu \mathrm{g} / \mathrm{cm}^{2}$ and $10 \mu \mathrm{g} / \mathrm{cm}^{2}$ (not for VN) respectively. Following surface treatment, plates were washed for $5 \mathrm{~min}$ in PBS and blocked with $1 \%$ bovine serum albumin (BSA) in PBS for $1 \mathrm{~h}$ at $37^{\circ} \mathrm{C}$. ARIP cells with $80 \%$ confluence were disattached with trypsin/EDTA and resuspended in F12K containing 10\% FCS. Cells were spun down at $250 \mathrm{xg}$ for $5 \mathrm{~min}$ and resuspended in serum-free F12K. Cells were seeded at a density of 3000 cells $/ \mathrm{cm}^{2}$ and cultured for 6 hours at $37^{\circ} \mathrm{C}$ in a humidified, $5 \% \mathrm{CO} 2$ atmosphere.

\subsection{Single Cell Morphology Analysis}

The cultured cells were stained with $2 \mathrm{uM}$ Calcein AM (Invitrogen, UK), a membranepermeant fluorescence viable cell indicator, for 45 minutes at room temperature. Images were captured from 4 random areas surrounding each centre of a well using an inverted fluorescent Leica DM IRB microscope at X200 magnification.

Fluorescence images were subsequently analysed using a highly standardised macro program language, QUIPS written in the Leica Qwin imaging software ((Leica, Bensheim, Germany). Briefly, the image analysis program was delicately designed to identify half maximal colour intensity so as to recognise the body of the single cell but not any background automatically. The intensity threshold was manually altered to reach the cell membrane. A binary editing function enabled the manual removal of artefacts that may have contributed to a false measurement. Once the area of choice had been accepted, single cell features (e.g. area, perimeter, number and roundness) were measured simultaneously according to the calibration of microscopic lens.

\subsection{ATP Luminescence Assay}

The determination of cell proliferation was carried out on the basis of a luminometric ATP measurement by means of the ATPlite ${ }^{\mathrm{TM}}-\mathrm{M}$ Luminescence Assay System (PerkinElmer, USA) according to the manufacturer's instruction. Luminescence was measured using a LUCY 1 luminometer (Anthos Labtech Instruments, Austria). Standard curves for individual culture of mammalian cell number were performed to confirm both linearity and sensitivity of the method.

\subsection{Surface Coverage Measurement}

Similar to the surface coating procedures described above, multiwell plates with tissue culture surface was 
coated with CN $\left(10 \mu \mathrm{g} / \mathrm{cm}^{2}\right), \mathrm{LN}\left(10 \mu \mathrm{g} / \mathrm{cm}^{2}\right), \mathrm{CN} 50 \%+$ LN 50\%, Matrigel matrix (BD Biosciences, UK), Poly L-Lysine (PLL; 0.01\% solution), PLL followed by CN, PLL followed by LN, PLL followed by CN $50 \%+$ LN $50 \%$, PLL followed by Matrigel, respectively. ARIP cells at a concentration of $2.5 \times 104$ cells $/ \mathrm{cm}^{2}$ were cultured on the above surfaces with F12K medium containing $10 \%$ FCS for 4 hours, and sequentially with Serum-free $\mathrm{F} 12 \mathrm{~K}$ medium supplemented with $2 \mathrm{~g} / 1 \mathrm{BSA}$, $1 \mathrm{~g} / \mathrm{l}$ ITS supplement, $10 \mathrm{mM}$ nicotinamide and P/S. Images were captured from the centre region of each well with the magnification of X100. Cell surface coverage analysis was similar to the measurement of single cell morphology mentioned above.

\subsection{Measurement of Insulin Content by Enzyme-Linked Immunosorbent Assay (ELISA)}

Cultured cells were washed three times for $10 \mathrm{~min}$ each in prewarmed fresh Krebs-Ringerbicarbonate buffer (KRBB; $115 \mathrm{mM} \mathrm{NaCl}, 24 \mathrm{mM} \mathrm{NaHCO} 3,5 \mathrm{mM} \mathrm{KCl}, 1$ $\mathrm{mM} \mathrm{MgCl}$, $2.5 \mathrm{mM} \mathrm{CaCl}$, $10 \mathrm{mM}$ HEPES, $\mathrm{pH}$ 7.4) with $0.1 \%$ BSA. Cells were then lysed directly by adding $0.5 \mathrm{ml}$ CelLyticTM-M mammalian cell lysis/ extraction reagent. After incubated for $15 \mathrm{~min}$ on a shaker, cell lysate was collected and centrifuged for $15 \mathrm{~min}$ at 1200 $\mathrm{xg}$ to pellet the cellular debris. Theprotein-containing supernatant was transferred to a chilled test tube and stored at $-80^{\circ} \mathrm{C}$ until being assayed for the presence of insulin using an Ultra Sensitive Rat Insulin ELISA Kit (Crystal Chem Inc, USA) according to the manufacturer's instruction.

\subsection{Measurement of Insulin Release Stimulated by Glucose}

Cells were washed three times with KRBB buffer. After pre-incubation with fresh KRBB buffer for another 30 minutes at $37{ }^{\circ} \mathrm{C}$, cells were subjected to $5.5 \mathrm{mM}$ and then $16.7 \mathrm{mM}$ glucose within the KRBB buffer for 1 hour. The amount of insulin released in supernatant was determined by rat insulin ELISA as mentioned above.

\subsection{Quantification of Cellular DNA Content}

Cultured cells in 96-well plates were washed with PBS and treated with $0.02 \%$ SDS in salinesodium citrate buffer at $37^{\circ} \mathrm{C}$ for $1 \mathrm{~h}$. Equal volume of $2 \mu \mathrm{g} / \mathrm{ml}$ Hoechst 33258 working solution was added in the above wells. $100 \mu \mathrm{l}$ of the above mixture was transferred to a fresh 96-well assay plate. Measurement of fluorescence was performed with a plate reader (Dynex technologies, UK) at excitation $\lambda 360 \mathrm{~nm}$ and emission $\lambda 460 \mathrm{~nm}$. Deoxyribonucleic acid sodium salt from calf thymus (Sigma, UK) was used as a DNA standard.

\subsection{Data Analysis}

The differences at various time points and experimental conditions were analysed by one-way ANOVA at $95 \%$ significance level for multiple comparisons using SPSS 11.5 (SPSS Inc., USA).

\section{RESULTS}

\subsection{Single Cell Morphology on ECM Protein-Coated Surfaces}

The first step in this research was to establish that the chosen blocking agent, $1 \%$ BSA, could decrease single cell area and perimeter when coated on to tissue culture treated plastic surfaces. Figure 1 confirmed the blocking action of BSA. Subsequently, effects of the four ECM protein-coated surfaces at a range of concentrations were compared. These ECM protein-coated surfaces altered both single cell features $(\mathrm{P}<0.01)$ when compared with BSA-coated surfaces. The treatment effects on both single cell area and single cell perimeter were in the order of $\mathrm{CN}>\mathrm{FN}>\mathrm{LN}>\mathrm{VN}$. For single cell area, among $\mathrm{CN}$ groups, there was a significant difference between the coating concentrations of $1 \mu \mathrm{g} / \mathrm{cm}^{2}$ and $0.1 \mathrm{ug} / \mathrm{cm}^{2}$ $(\mathrm{P}<0.01)$; and the single cell area difference between them was approximately $200 \mu \mathrm{m}^{2}$. No difference was found between $10 \mu \mathrm{g} / \mathrm{cm}^{2}$ and $1 \mu \mathrm{g} / \mathrm{cm}^{2}$ of CN groups. Among FN groups, the three coating concentrations showed similar results. Among LN groups, $10 \mu \mathrm{g} / \mathrm{cm}^{2}$ of LN-coated surface resulted in higher single cell area compared with the other two lower concentrations $(\mathrm{P}<0.01)$; no difference was found between $0.1 \mathrm{ug} / \mathrm{cm}^{2}$ and $1 \mathrm{ug} / \mathrm{cm}^{2}$. Among VN groups, the results of $0.1 \mathrm{ug} /$ $\mathrm{cm}^{2}$ and $1 \mathrm{ug} / \mathrm{cm}^{2}$ concentrations were similar. The feature of single cell perimeter produced similar patterns of treatment effects on single cell area. When single cell roundness was estimated, surfaces coated with three concentrations of $\mathrm{CN}$ increased this feature, and 10 $\mu \mathrm{g} / \mathrm{cm}^{2}$ of $\mathrm{CN}$-coated surface appeared to induce the highest ( $\mathrm{P}<0.01$ vs BSA group).

Morphologically, on the four ECM protein-coated surfaces, ARIP cells showed increased cell membrane spreading and cell protuberance (Figure 2). It appeared that the effect of CN, FN and LN was stronger than VN when they were used to coat tissue culture polystyrene surface. These results indicated that four types of ECM protein-coated surfaces could expand the morphological structures of single ARIP cell in vitro.

In a follow-up experiment, ARIP cells at a density of $1.5 \times 104 \mathrm{cells} / \mathrm{cm}^{2}$ were cultured under the equivalent surface-coated conditions described above and in serum-free medium for 96 hours. Results showed that the viability of cells decreased severely, and there were just a few viable cells left surrounded by large amounts of cellular debris (data not shown). It appeared difficult for cells to reach confluence. As a control, cells in medium 

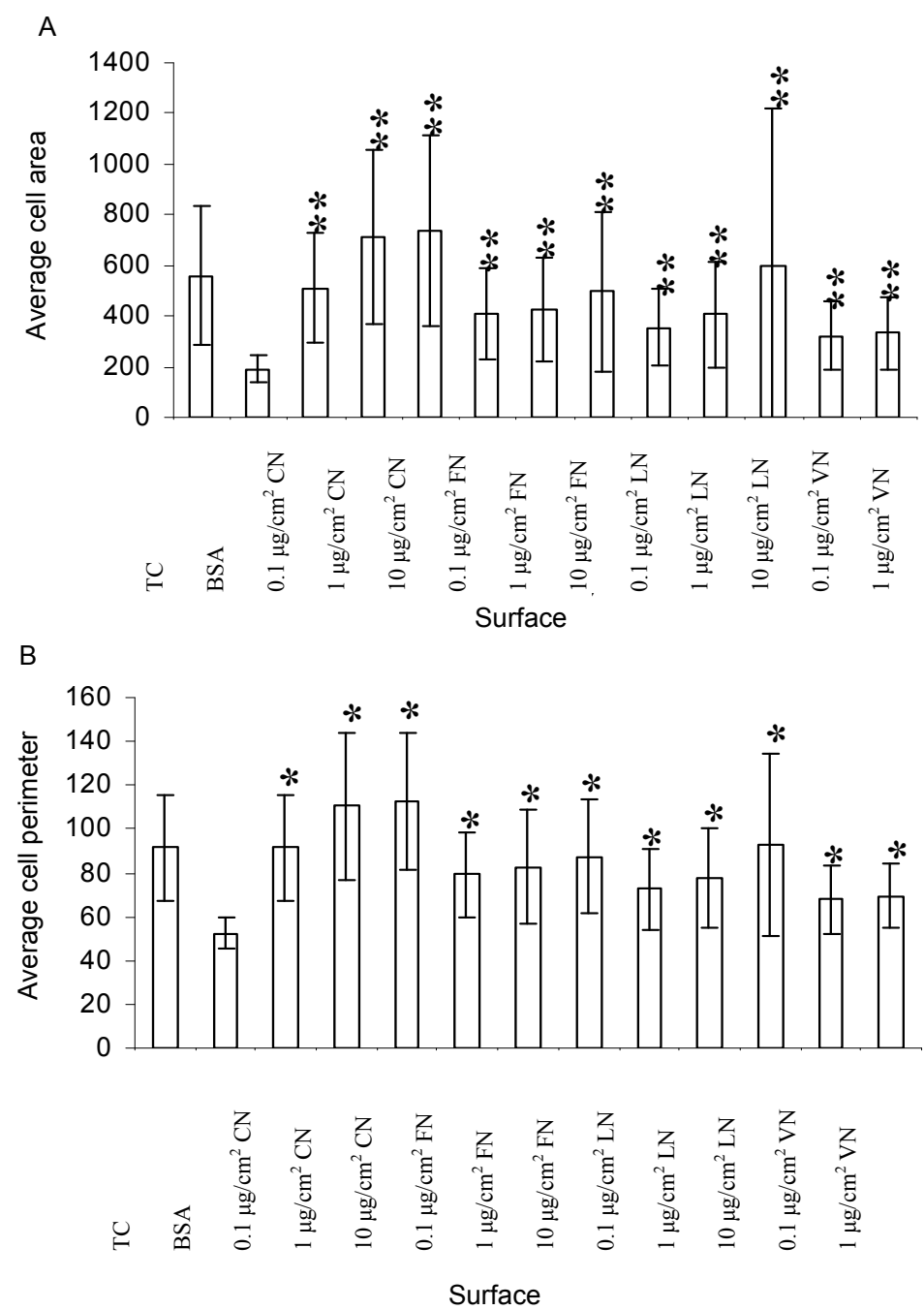

Figure 1. Effect of ECM protein-coated surfaces on the single cell area (A) and perimeter (B) of ARIP cells. ARIP cells were seeded on surfaces as indicated at a density of 3000 cells $/ \mathrm{cm}^{2}$ and cultured for 6 hours in F12K medium respectively. Each bar was given as means \pm SD. Significant differences are indicated as $* * \mathrm{P}<0.01$ vs. BSA.

containing $10 \%$ FCS showed normal growth. Therefore, for the long-term culture, it was not possible to maintain growth of ARIP cells on the ECM-protein coated surfaces in absolute serum-free medium without providing any extra essential component.

\subsection{Growth of ARIP Cells in Defined Serum-free Medium}

In order to provide a suitable serum-free culture environment for ARIP cells without using FCS, this work investigated the possibility to defining and optimising serum-free medium with known functional supplements including ITS, BSA, nicotinamide, KGF and GLP-1. As shown in Figure 3, when ARIP cells were cultured at a low seeding density $\left(1.5 \times 104\right.$ cells $\left./ \mathrm{cm}^{2}\right)$, and cultured over 96 hours, there were significant differences in cell proliferation between normal culture medium containing $10 \%$ FCS (named as FCS group) and all serum-free cultivation groups $(\mathrm{P}<0.01)$. This suggested that it was difficult to establish cell proliferation within serum-free media if the cell density was too low. At a higher density studied $\left(3 \times 104 \mathrm{cells} / \mathrm{cm}^{2}\right)$, none of the serum freegroups supported cell proliferation as sufficiently as FCS group. However, cell proliferation in the FI F12K medium supplemented with BSA, ITS and nicotinamide (named as FI) or F12K medium supplemented with BSA, ITS, nicotinamide and KGF (named as FII) appeared to behigher than other serum-free groups. The addition of KGF in FII group did not show any additiveeffect. At the highest density studied, $6 \times 104 \mathrm{cells} / \mathrm{cm}^{2}$, after tissue culture for 96 hours, there was no difference among FCS, FI and FII groups, suggesting that FI and FII provided a tissue 

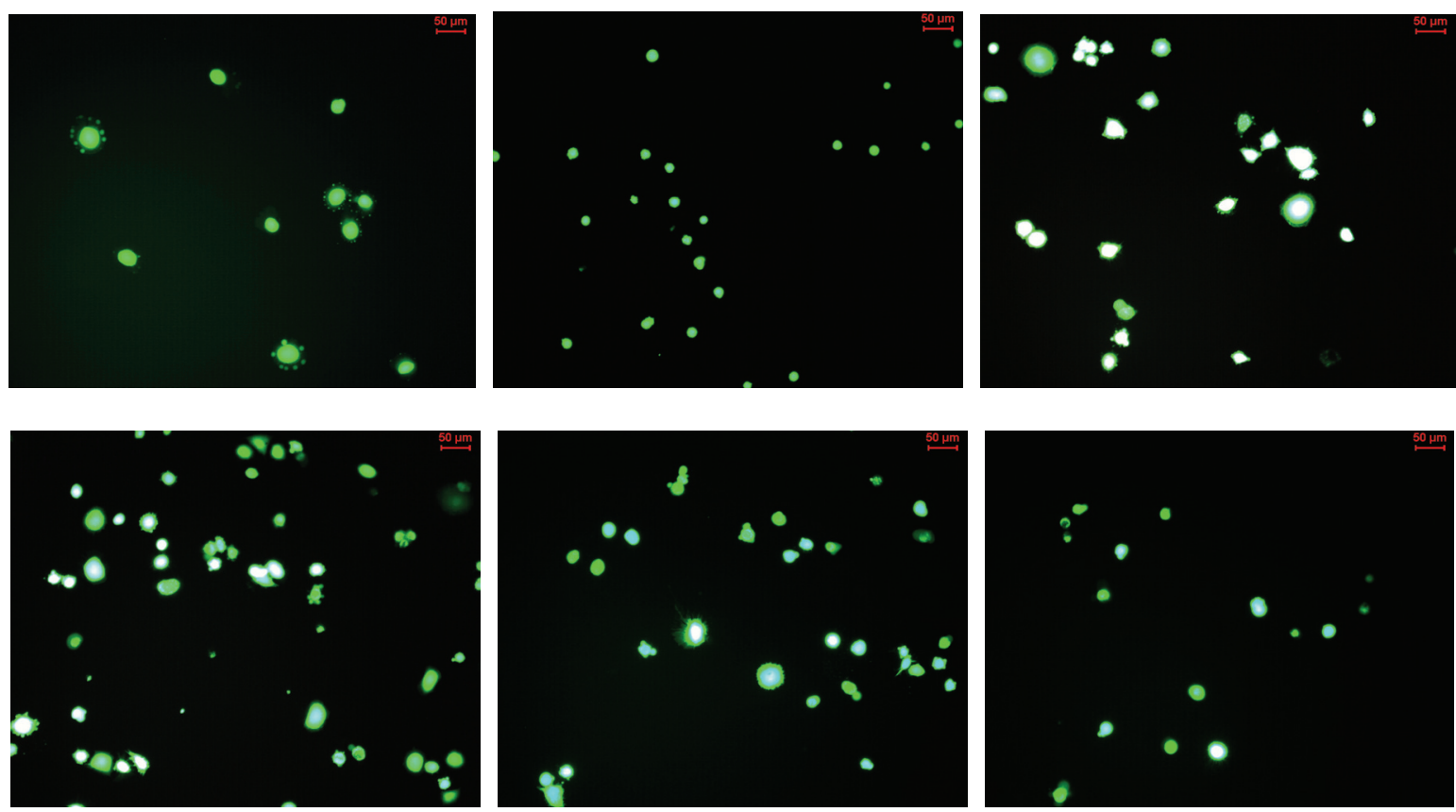

Figure 2. Morphology of ARIP cells cultured on different surfaces with F12K medium plus P/S for 6 hours. Magnification: X200. Cells were stained with $2 \mathrm{uM}$ of Calcein AM. A. TC surface. B. $1 \%$ BSA surface. C. $10 \mu \mathrm{g} / \mathrm{cm}^{2} \mathrm{CN}$ surface. D. $10 \mu \mathrm{g} / \mathrm{cm}^{2}$ FN surface. E. $10 \mu \mathrm{g} / \mathrm{cm}^{2} \mathrm{LN}$ surface. F. $10 \mu \mathrm{g} / \mathrm{cm}^{2} \mathrm{VN}$ surface. The scale bar was $50 \mu \mathrm{m}$.

A

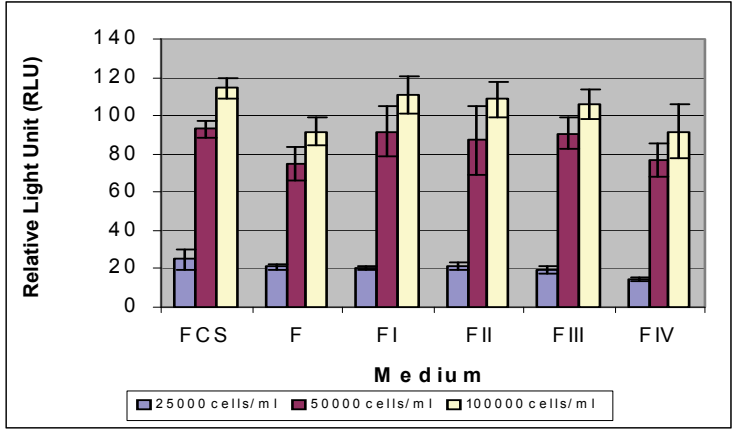

B

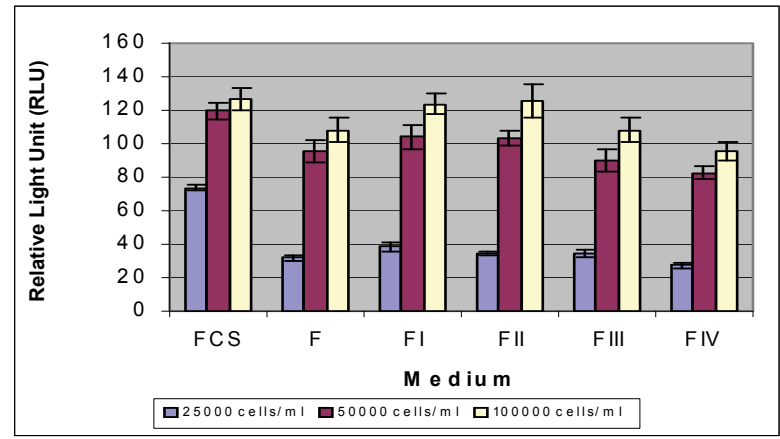

Figure 3. Relative light unit (RLU) by ATP assay which quantitatively indicates relative number of ARIP cells. FCS: F12K+10\% FCS; F: F12K; FI: F12K+BSA+ITS+nicotinamide; FII: FI+ 10ng/ml KGF; FIII: FI+10nM GLP-1; FIV: $\mathrm{FI}+\mathrm{KGF}+\mathrm{GLP}-1$. Each value was give as mean \pm SD from 6 observations. A. 48 hours. B. 96 hours. Significant differences are indicated as $* \mathrm{P}<0.05 ; * * \mathrm{P}<0.01$ and $* * * \mathrm{P}<0.001 \mathrm{vs}$. FCS.

culture environment equivalent to culture medium containing FCS. The group of F12K medium supplemented with 10nM GLP-1 (named as FIII) did not improve cell proliferation even compared with the group of absolute serum-free medium (F group). Moreover, in the group of serum-free medium supplemented with both KGF and GLP-1 (named as FIV), ARIP cells showed the lowest proliferation rate compared with other serum-free culture conditions. These results implied that GLP-1 might play an inhibitive role in proliferation of ARIP cells especially in the presence of KGF. Overall, during the 96-hour period studied, reproduction or proliferation of ARIP cells under serum-free conditions was density- dependent. The supplements of BSA, ITS and nicotinamide together were found to maintain cell proliferation at equivalent levels to FCS.

\subsection{Estimation of Cell Coverage in the Presence of ECM Protein-Coated Sur- faces and Defined Serum-Free Medium}

This study investigated the overall cell growth of ARIP cells in the presence of ECM proteins and defined serum-free medium by estimating the surface coverage of culture at three time points (4, 48 and 96 hours). As shown in Figure 3, after monolayer culture for 96 hours, the surfaces treated with $\mathrm{CN}$ and LN produced cell cov 


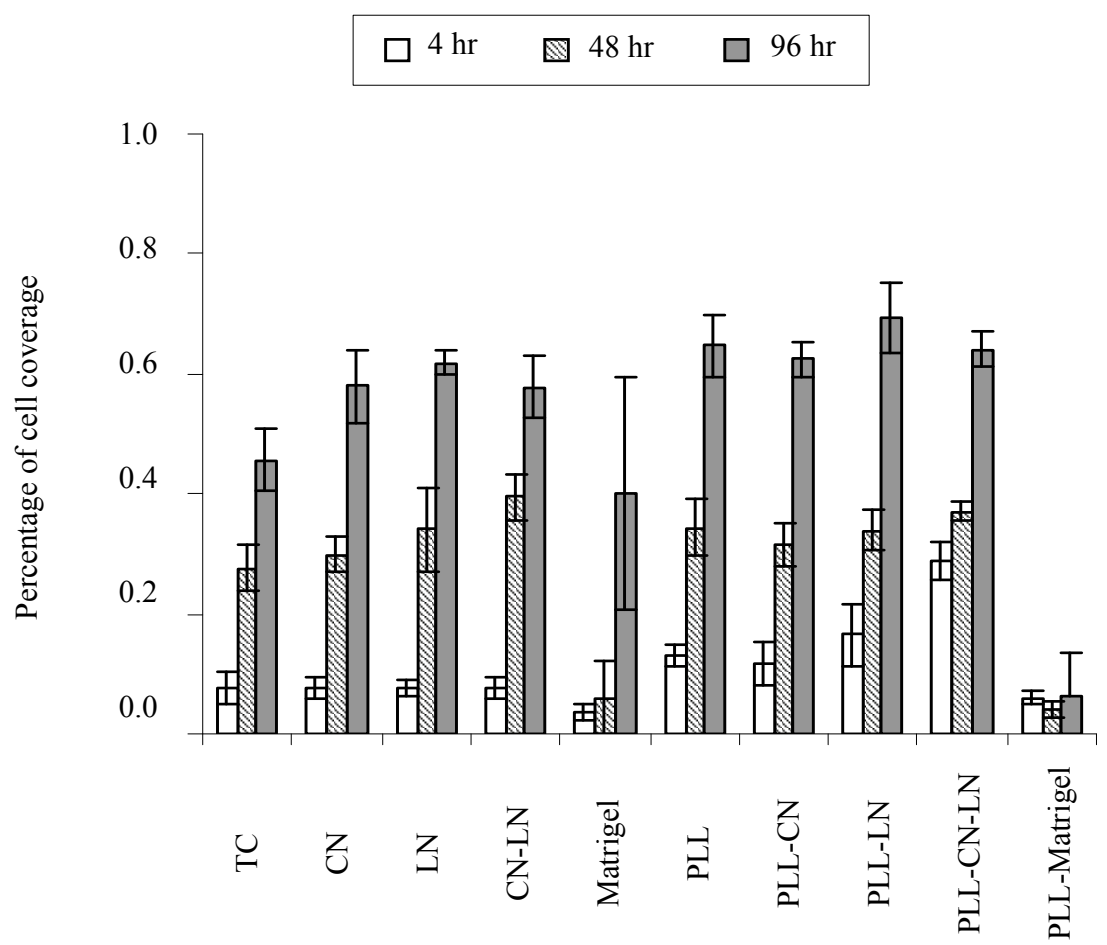

Surface

Figure 4. Surface coverage of ARIP cells. Cells were cultured in F12K supplemented with BSA, ITS, nicotinamide and $\mathrm{P} / \mathrm{S}$. Each value was given as means \pm SD from 3 individual observations. TC: Tissue culture surface. $\mathrm{CN}$ : collagen I coated surface. $\mathrm{LN}$ : laminin coated surface. $\mathrm{CN}+\mathrm{LN}$ : 50\% collagen I and 50\% laminin coated surface. Matrigel: Matrigel coated surface. PLL: $0.01 \%$ ploy-l-lysine coated surface. PLL $+\mathrm{CN}$ : poly-1-lysine surface was further coated with collagen I. PLL+LN: poly-l-lysine surface was further coated with laminin. PLL+CN+LN: poly-l-lysine surface was further coated with 50\% collagen I and 50\% laminin. PLL+Matrigel: poly-1-lysine surface was further coated with Matrigel. Significant differences are indicated as $* \mathrm{P}<0.05$;

$* * \mathrm{P}<0.01$ or $* * \mathrm{P}<0.001$.

erage of approximately $60 \%$, while the percentage was approximately $46 \%$ on tissue culture surface. Thus, $\mathrm{CN}$ and $\mathrm{LN}$ coated surfaces improved the cell surface coverage $(\mathrm{P}<0.05)$. PLL $(0.01 \%)$ enhanced cell coverage slightly after culture for 96 hours no matter whether surfaces were coated with ECM proteins. Matrigel inhibited cell coverage either on its own or on PLL pre-coated surface. Moreover, the majority of ARIP cells appeared rounder in morphology and difficult to spread upon Matrigel-coated surfaces. In addition, distribution of ARIP cells on Matrigel-coated surfaces was patchy and uneven (Figure 3). In some of the captured images in the Matrigel-coated-surface group, a few of cells could be found. The addition of PLL did not alter the effect of Matrigel.

On the laminin-coated surfaces, the surface coverage increased by approximately $16 \%$ in the absence of PLL and $23 \%$ in the presence of PLL compared with nontreated tissue culture surface, suggesting the positive role of LN in the overall status of ARIP cells in defined serum-freemedium. The surface treated with $\mathrm{CN}$ and $\mathrm{LN}$ together appeared to show an effect after 48 hours, but after incubation for 96 hours, it was similar to the surfaces coated with $\mathrm{CN}$ or LN separately. Furthermore, the equivalent experiments were repeated using a lower cell density, $3 \times 104 \mathrm{cell} / \mathrm{cm}^{2}$, and the results also demonstrated that LN significantly promoted cell surface coverage, andMatrigel inhibited cell growth and surface coverage.

\subsection{Insulin Production and Gene Expression under Differentiation Conditions}

Immunofluorescence was carried out to identify insulin-producing ARIP cells induced by GLP-1. As shown in Figure 53, in the presence of $10 \mathrm{nM}$ GLP-1 within serum-free medium, approximately $20-30 \%$ of ARIP cells were insulin positive, suggesting that GLP-1 was able to direct insulin-positive cell formation. 
In order to investigate whether these insulin-positive cells can produce insulin, the insulin content within ARIP cells was carried out. Meanwhile, total cellular DNA content was applied to normalize insulin content and indicate cell proliferation. As shown in Figure 5A, after incubation for 72 hours, surfaces coated with ECM proteins studied resulted in large increases in total DNA content. The cell culture upon laminin-coated surface resulted in the highest DNA level, which was approximately 3 -fold higher than that upon normal tissue culture plastic surface. Because the total DNA content reflects the cell number in each group, the data indicated that ECM proteins play a role in increasing cell number over the period studied. Furthermore, as shown in Figure 5B, all the ECM protein-coated surfaces appeared to improve the total insulin content in ARIP cells over a 72-hour period studied. Collagen-coated surface appeared to have the highest impact on insulin production when compared with surfaces coated with either fibronectin or laminin. After insulin production is normalisation by DNA content as shown in Figure 5C, it appeared that only the collagen-coated surface had a stimulative effect on insulin production given the same size of cell population. The collagen-coated surface showed approximately 1.8-fold higher normalised insulin content in ARIP cells than the uncoated tissue culture surface.

The presence of insulin gene expression in ARIP cells was measured using RT-PCR. As shown in Figure 6, despite the strong expression of $\beta$-actin as an endogenous control, insulin gene expression was weak in the entire groups studied. It appeared that ARIP cells upon collagen coated surface resulted in slightly higher insulin gene expression. Expressions of the other genes such as PDX-1 were not identified. Experiments were repeated at least three times and similar results were obtained. To ensure the gene primers used in RT-PCR were specific, RNA samples were isolated from RIN-m5F cells, a rat insulin-producing cell line, and used as controls. Results showed that RIN-m5F cells strongly expressed insulin and PDX-1 genes under identical RT-PCR conditions thus confirming the efficacy of the technique employed.

Given the combination conditions including collagencoated surface, GLP-1 and defined serum-free medium, and after incubation for 72 hours, the ARIP cells were challenged with $5.5 \mathrm{mM}$ and $16.7 \mathrm{mM}$ of glucose. As shown in Figure 7, there appeared to be little difference in insulin secretion response to the two concentrations of glucose.

\section{DISCUSSION}

The work demonstrates that tissue culture polystyrene surfaces coated with different types of ECM proteins have effects on the morphological features of single ARIP cell. These changes can be detected by 5 hours.
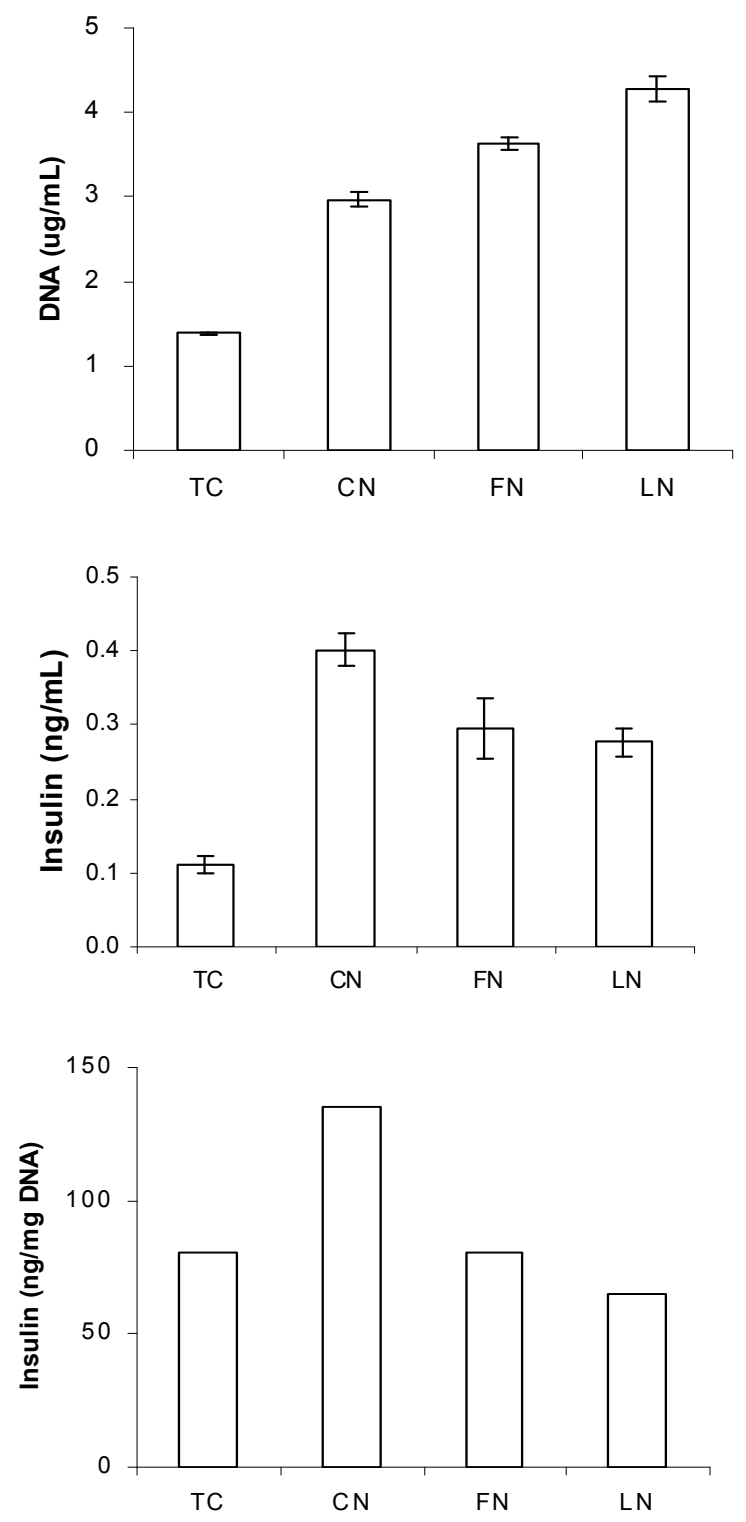

Figure 5. Insulin released by ARIP cells with response to ECM -protein-treated surfaces. Cells were cultured for 48 hours in F12K medium supplemented with ITS, BSA nicotinamide and GLP-1. TC: TC surface. CN: $10 \mu \mathrm{g} / \mathrm{cm}^{2} \mathrm{CN}$ coated surface. FN: $10 \mu \mathrm{g} / \mathrm{cm}^{2}$ FN coated surface. LN: $10 \mu \mathrm{g} / \mathrm{cm}^{2} \mathrm{LN}$ coated surface. Cell density: $5 \times 104$ cells $/ \mathrm{cm}^{2}$. Each value was given as mean \pm SD from 3 individual observations.

Their treatment effects on both single cell area and single cell perimeter were in the order of collagen Type I $>$ fibronectin $>$ laminin $>$ vitronectin. Of the four ECM proteins studied, collagen-coated surface achieves the highest level, for example, the increase of single cell area is 2.7-3.8 fold compared with the BSA-coated surface as a control. Previous studies have identified the tripeptide RGD is located in all the four ECM protein types, and the RGD domain in the ECM proteins serves as a cell 


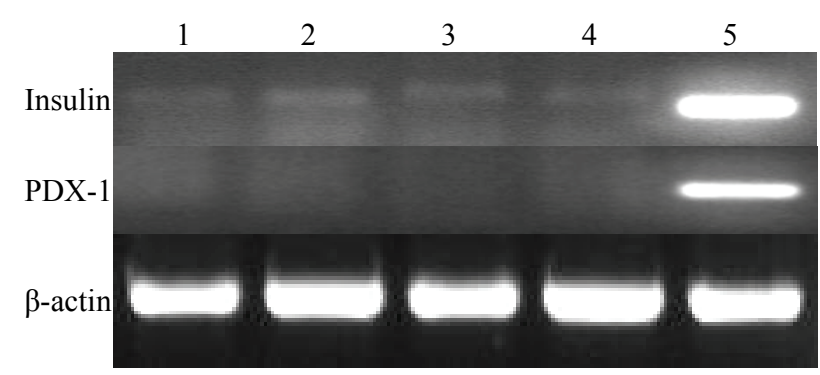

Figure 6. Expression of insulin and PDX-1 genes in ARIP cells following incubation for 72 hours in defined serum-free medium plus $10 \mathrm{nM} \mathrm{GLP}-1$ and upon surfaces indicated. Lanes from 1 to 4 are RT-PCR products from ARIP cells. Lane 1:TC surface. Lane 2: collagen I coated surface. Lane 3: fibronectin coated surface. Lane 4: laminin coated surface. Lane 5:gene expression in RIN-m5F cells (an insulin-producing cell line from insulinoma) and used to validate the RT-PCR assay of each gene.

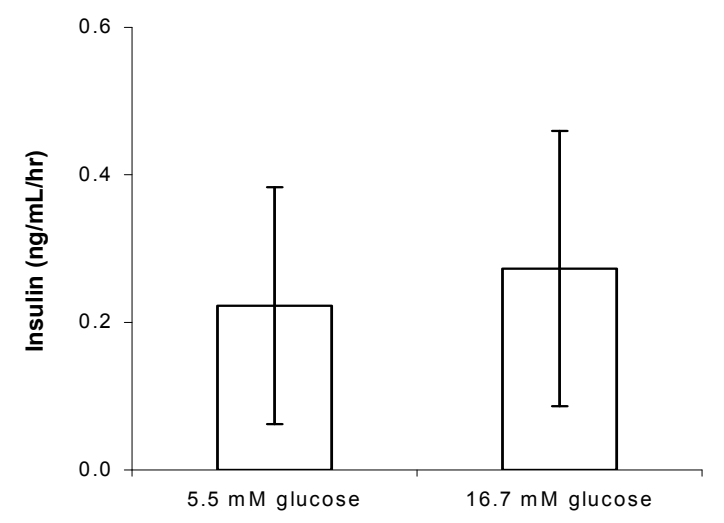

Figure 7. Insulin secretion in ARIP cells with response to glucose stimulation. Cells were cultivated for 72 hours in defined serum-free medium plus $10 \mathrm{nM} \mathrm{GLP}-1$ and upon collagen coated surface. Each value was given as mean \pm SD from 5 individual observations.

recognition site and plays a role in cell spreading through its binding to integrins [35]. However, as these four ECM proteins bind to different integrin patterns, this may explain their different effects on ARIP cells. Vitronectin has the weakest effects according to our data, it may be possible that vitronectin mainly binds to $\alpha \mathrm{v} \beta 3$ and $\alpha v \beta 5$ integrins, which are not as effective or abundant as the other integrins [31].

Because without FCS, serum-free medium is not able to maintain the survival of ARIP cells upon ECM-protein coated surfaces, the work presents an optimal serum-free culture environment for the purpose of using ECM proteins effectively. Moreover, as proliferation of ARIP cells is density-dependent. The initial seeding density of cells should be high enough (e.g. $6 \times 10^{4}$ cells/ $\mathrm{cm}^{2}$ ) so as to maintain cells under serum-free medium conditions. This sufficient cell density may encourage cells interact effectively, thus enhancing survival of the total population. The impact of KGF on proliferation appears to be minimal when ARIP cells are cultured under serum-free conditions. However, KGF has been identified as an important growth factor of epithelial cells $[31,43]$. A previous study also suggests that KGF has a potential to induce pancreatic ductal cell proliferation in vivo [45]. The reason KGF doesn't not play a role in ARIP cells proliferation may be because ARIP are distinctive from primary pancreatic epithelium in terms of their origin and cellular characteristics. For example, the pancreatic regenerating gene proteins are mitogenic to primary cultures of ductal cells, but compared with their effects on the primary cultured ductal cells, these proteins were 100-fold less potent on ARIP cells [46].

Our results show that GLP-1 inhibits the proliferation of ARIP cells. This may be the result of transdifferentiation of pancreatic ductal cells induced by GLP-1 $[4,5,15]$. A previous study also provides evidence that GLP-1 promotes islet-cell neogenesis from pancreatic ductal cells in a type 2 diabetic rodent model [30]. Due to the inhibitory effect of GLP-1 on ductal cell proliferation, GLP-1 should be supplied at differentiation but not proliferation stage.

Surface coverage pattern of adhesive cells is determined by total cell number, individual cell features and surface properties in theory, thus it can reflect the dynamics of the overall cell performance under particular tissue culture conditions $[1,12]$. The ECM provides a backbone to influence the attachment of other proteins or influence cell adhesion directly via embedded cell signalling. Therefore, the coverage of monolayer cells on ECM protein-coated surfaces can indicate the overall patterns of cell status as consequence of adhesion, migration, proliferation and differentiation. Our results demonstrates that when monolayer ARIP cells are cultured for 4 days in optimised serum-free medium, surface coated with laminin has a significant supportive effect on coverage of ARIP cells. Because laminin has been demonstrated to improve the insulin accumulation and preservation of pancreatic endocrine cells $[17,18,19]$, it can be employed when cells with pancreatic ductal characteristics are differentiated into an insulin-producing phenotype.

Collagen-coated surface appeared to increase the percentage of cell coverage especially in the presence of poly-L-lysine. A previous study has indicated that Collagen is useful for the culture of adult primary pancreatic epithelial cells from the main duct [27]. However, in embryonic pancreatic epithelia, laminin but not collagen has been demonstrated to induce duct formation [23]. Therefore, the exact signalling pathways of collagen and laminin for cell differentiation should be further investigated. 
Poly-lysine can enhance electrostatic interaction between negatively-charged ions of the cell membrane and positively-charged surface ions of attachment factors on tissue culture plastic surface. When adsorbed to the culture surface, it may increase the number of positively charged sites available for cell binding. It has been known to be useful for enhancing effects of surface coating with ECM proteins. Our results confirm that Poly-L-lysine can improve the percentage of cell coverage on culture surfaces coated with selective ECM proteins.

In the presence of defined serum-free medium, Matrigel-coated surface inhibits the coverage of ARIP cells significantly. Indeed this inhibition can be detected even after 4 hours. In order to avoid the potential effects of growth factors in Matrigel, growth factor-reduced Matrigel has also been used, however, the inhibitive effect induced by Matrigel cannot disappear. Matrigel has been found important to promote the formation of islet-like clusters from primary pancreatic ductal epithelial cells [3]. It is possible that Matrigel induces the differentiation of pancreatic ductal cells leading to a decreased proliferation. However, due to the complex formulation of Matrigel, the exact signalling pathway needs to be further investigated.

In the presence of GLP-1, ARIP cells show different morphological structures and a loss of their typical cobblestone-like morphology. This morphological change may be due to the regulation of metabolism activities or induced differentiation. GLP-1 has been reported to induce insulin-producing cell differentiation from pancreatic acinar AR42J and ductal ARIP cells $[15,47]$. For example, exposure of rat AR42J cells to GLP-1 over 2 days result in an initial increase in levels of cyclic adenosine monophosphate and cellular proliferation, followed by cessation of proliferation and expression of the islet-associated hormones, insulin, glucagon, and somatostatin, in up to $50 \%$ of cells [47]. Furthermore, GLP-1 treatment also induces expression of glucose transporter 2 and glucokinase genes, in association with the capacity to secrete insulin in a glucose-dependent manner [47]. Therefore, the morphological change found here may be associated with transdifferentiation of ARIP cells. Interestingly, defined serum-fee medium also resulted in a slight change in morphology of ARIP cells. As nicotinamide has been considered capable of stimulating insulin-producing cell differentiation in other progenitor cell types [7,29], this may partly explain the morphological change of ARIP cells in defined serum-free medium. Immunofluorescence data in this study indicate that $20-30 \%$ of ARIP cells can obtain an insulin-positive phenotype after exposure to GLP-1. The insulin content of ARIP cells in the presence of GLP-1 can also be detected. Thus, it confirms that GLP-1 has the capability of converting ARIP cells into insu- lin-producing cells to some extent. The combination of the defined serum-free medium and GLP-1 leads to the maximum insulin production rate. This is as expected, because the defined serum-free medium is able to sustain the maximum growth of ARIP cells in a serum-free environment.

After the treatment with GLP-1 and/or defined serum-free medium, the gene expression of insulin in ARIP cells is observed at a low level. This indicates that the insulin content observed by ELISA is not from potential contamination or uptake that has been described in a previous study on the insulin-producing cell differentiation of embryonic stem cells [37]. The result obtained here appears similar to a previous study, which demonstrates the weak expression of insulin gene in GLP-1-induced ARIP cells by northern blot analysis [15]. However, no insulin gene expression was detected by another similar study [21]. Moreover, the expression of other relevant genes such as PDX-1 is not detected here. Therefore, although the insulin gene, not normally present in ARIP cells, is expressed, it is difficult to relate this study to the observations by other relevant studies.

In addition, although the role of GLP-1 in insulinproducing cell formation is confirmed, it remains unclear as to how GLP-1 triggers the insulin production in ARIP cells. Previous studies suggests that the initial step of GLP-1 action requires identification and binding of the peptide to the GLP-1 receptor, which is in the super-family of G protein-coupled receptors [41]. Activation of the GLP-1 receptor results in the stimulation of adenylyl cyclase, leading to an increase in intracellular cyclic adenosine monophosphate (cAMP) and the cAMP-dependent protein kinase A (PKA) activation in the pancreatic tissue $[10,11,14,22]$. However, the gene expression of GLP-1 receptor remains controversial as described in previous studies $[15,21]$. It is also reported that the action of GLP-1 depends on the expression of PDX-1. However, PDX-1 gene expression is not detected in this study, which is consistent with two of the previous studies $[21,36]$. Relevant studies on other adult non- $\beta$ cells may provide additional clues. For example, the PDX-1 expression in the duodenal tissue is stronger than in intestinal epithelial cells, but GLP-1 could induce insulin production in intestinal epithelial cells but not in duodenum cells [38].

On the other hand, GLP-1 has been suggested to upregulate expression of some other transcription factors such as Neurogenin 3 but not PDX-1 during insulin expression [38]. A study using adult hepatic progenitor cells has shown that the acute insulin secretion of non-PDX-1- expressing cells can be enhanced by GLP-1 in a time-dependent manner, though the effect of GLP-1 is strengthened in the presence of PDX-1 [25]. Indeed, there is no sufficient evidence to show that GLP-1 increases the PDX-1 gene expression during insulin producing cell conversion from other adult cell types. Taken 
together, during the induction of insulin-producing-cell generation using adult progenitor cells, the role of GLP-1 may be enhanced by PDX-1 gene expression, but the exact signalling pathway of GLP-1 remains unclear.

\section{CONCLUSIONS}

In the presence of GLP-1 and defined serum-free medium, the total amount of insulin content in ARIP cells significantly increases upon the surfaces coated with ECM proteins including collagen, fibronectin and laminin. Meanwhile, comparison of total DNA content indicates that ECM-protein coated surfaces play a role in cell duplication, possibly through improved single cell spreading. After normalisation by DNA content, only collagen-coated surface appears to stimulate the insulin production given the same cell population size. The data obtained from gene expression also show that the insulin gene expression in ARIP cells upon collagen-coated surface appears slightly stronger. To date, there is still no sufficient information to determine how important ECM proteins are to insulin-producing cell formation from other cell types. Therefore, more experiments need to be carried out before the roles of ECM proteins can be fully illustrated. In particular, the distribution and activition of integrins may be important in revealing the profound function of these proteins.

\section{ACKNOWLEDGEMENT}

This work was funded by the EPSRC. We thank Professor Kevin Shakesheff, Dr Sue Chan, Dr Richard Pearson and Mr Darryl Jackson for their critical advice and technical assistance.

\section{REFERENCES}

[1] B. T. M. Baharloo and D. Brunette, (2005) Substratum roughness alters the growth, area, and focal adhesions of epithelial cells, and their proximity to titanium surfaces, $\mathrm{J}$ Biomed Mater Res A, 74, 12-22.

[2] S. B. Weir, L. A. Baxter, G. T. Schuppin, and F. E. Smith, (1993) A second pathway for regeneration of adult exocrine and endocrine pancreas: A possible recapitulation of embryonic development, Diabetes, 42, 1715-1720.

[3] S. T. B. Weir, M. Weir, G. C. Tatarkiewicz, K. Song, K. H. Sharma, and A. O'Neil, (2000) In vitro cultivation of human islets from expanded ductal tissue, Proc Natl Acad Sci, 97, 7999-8004.

[4] A. H. Bulotta, H. Anastasi, E. Bertolotto, C. Boros, L. G. Di Mario, U. Perfetti, R. Silver, K. Yao, F. Zenilman, M. E. Chen, and T. H. Magnuson, (2002) Cultured pancreatic ductal cells undergo cell cycle re-distribution and beta-cell-like differentiation in response to glucagon-like peptide-1, J Mol Endocrinol, 29, 347-360.

[5] A. P. Bulotta, H. R. Hui, and L. G. Boros, (2003) GLP-1 stimulates glucose-derived de novo fatty acid synthesis and chain elongation during cell differentiation and insulin release, J. Lipid Res, 44, 1559-1565.

[6] L. A. Chen, M. C. Alam, T. Miyaura, C. Sestak, A. O'Neil, J. Unger, and C. B. Newgard, (1992) Factors regulating islet regeneration in the post-insulinoma NEDH rat, Adv Exp.Med Biol, 321, 71-80, 81-74.

[7] L. B. Chen, X. B. Jiang, and L. Yang, (2004) Differentiation of rat marrow mesenchymal stem cells into pancreatic islet beta-cells, World J Gastroenterol, 10, 30163020.

[8] B. S. Chertow, N. Q. Goking, and H. K. Driscoll, (1997) Effects of all-trans-retinoic acid (ATRA) and retinoic acid receptor (RAR) expression on secretion, growth, and apoptosis of insulin-secreting RINm5F cells, Pancreas, 15, 122-31.

[9] E. A. Clark and J. S. Brugge, (1995) Integrins and signal transduction pathways: The road taken, Science, 268, 233-239.

[10] W. G. R. Ding, E. Rorsman, P. Buschard, and J. K. Gromada, (1997) Glucagon-like peptide I and glucose- dependent insulinotropic polypeptide stimulate $\mathrm{Ca} 2+$ induced secretion in rat alpha-cells by a protein kinase A-mediated mechanism, Diabetes, 46, 792-800.

[11] H. C. S. Fehmann, M. and Goke, B. (1994) Interaction of glucagon-like peptide-I (7-37) and somatostatin-14 on signal transduction and proinsulin gene expression in beta TC-1 cells, Metabolism, 43, 787-792.

[12] P. Feugier, R. A. Black, J. A. Hunt, and T. V. How, (2005) Attachment, morphology and adherence of human endothelial cells to vascular prosthesis materials under the action of shear stress, Biomaterials, 26, 1457-1466.

[13] R. U. Gao, J. Pulkkinen, M. A. Lundin, K. Korsgren, and T. Otonkoski, (2007) Characterization of endocrine progenitor cells and critical factors for their differentiation in human adult pancreatic cell culture, Diabetes, 52, 2003-2015.

[14] D. H. Gefel, G. K. Mojsov, S. Habener, and G. C. Weir, (1990) Glucagon-like peptide-I analogs: effects on insulin secretion and adenosine 3',5'-monophosphate formation, Endocrinology, 126, 2164-2168.

[15] H. Hui, C. Wright, and R. Perfetti, (2001) Glucagon-like peptide 1 induces differentiation of islet duodenal homeobox-1-positive pancreatic ductal cells into insulin-secreting cells, Diabetes, 50, 785-96.

[16] N. W. Jessop, (1980) Characteristics of two rat pancreatic exocrine cell lines derived from transplantable tumors, In vitro, 16, 212.

[17] F. X. Jiang, (2005) Laminin-1 and epidermal growth factor family members costimulate fetal pancreas cell proliferation and colony formation, Differentiation, 73, 45-49.

[18] F. X. C. Jiang, D. S. DeAizpurua, and L. C. Harrison, (1999) Laminin-1 promotes differentiation of fetal mouse pancreatic beta-cells, Diabetes, 48, 722-730.

[19] F. X. Jiang and L. C. Harrison, (2001) Regulation of laminin 1-induced pancreatic beta-cell differentiation by alpha6 integrin and alpha-dystroglycan, Mol Med, 7, 107-114.

[20] C. Q. Lin, (1993) Multi-faceted regulation of cell differentiation by extracellular matrix, Faseb, 7, 737-743.

[21] H. K. G. Liu, B. D. Gault, V. A. McCluskey, J. T. McClenaghan, N. H. O'Harte, and P. R. Flatt, (2004) N-acetyl-GLP-1: A DPP IV-resistant analogue of glucagon-like peptide-1 (GLP-1) with improved effects on 
pancreatic beta-cell-associated gene expression, Cell Biol Int., 28, 69-73.

[22] M. W. Lu, M. B. Leng, and A. E. Boyd, (1993 The role of the free cytosolic calcium level in beta-cell signal transduction by gastric inhibitory polypeptide and glucagonlike peptide I (7-37), Endocrinology, 132, 94-100.

[23] T. S. C. Maldonado, C. A. Kadison, A. S. Alkasab, S. L. Longaker, and G. K. Gittes, (2000) Basement membrane exposure defines a critical window of competence for pancreatic duct differentiation from undifferentiated pancreatic precursor cells, Pancreas, 21, 93-96.

[24] C. Miyaura, L. Chen, M. Appel, T. Alam, L. Inman, S. Hughes, D. Milburn, J. L. Unger, and C. B. Newgard, (1991) Expression of reg/PSP, a pancreatic exocrine gene: relationshipto changes in islet beta-cell mass, Mol Endocrinol, 5, 226-234.

[25] N. S. N. Nagata, T. Mitaka, T. Katakai, T. Yamato, E. Miyazaki, J. Tabata, Y. Sugai, and A. Shimizu, (2004) In vitro induction of adult hepatic progenitor cells into insulinproducing cells, Biochem Biophys Res Commun, 318, $625-630$.

[26] C. O. Welsh, (2001) Long-term culture in matrigel enhances the insulin secretion of fetal porcine islet-like cell clusters in vitro, Pancreas, 22, 157-163.

[27] D. S. Oda, C. E. Nguyen, T. D. Swenson, and S. P. Lee, (1998) Culture of human main pancreatic duct epithelial cells, In Vitro Cell Dev Biol Anim, 34, 211-216.

[28] T. Otonkoski, G. M. Beattie, M. I. Mally, C. Ricordi, and A. Hayek, (1993) Nicotinamide is a potent inducer of endocrine differentiation in cultured human fetal pancreatic cells, J Clin Invest, 92, 1459-1466.

[29] T. Otonkoski, J. Ustinov, M. A. Huotari, E. Kallio, and P. Hayry, (1997) Nicotinamide and sodium butyrate for the induction of fetal porcine beta-cell differentiation prior to transplantation, Transplant Proc,29, 2045.

[30] R. A. H. Perfetti, (2004) The role of GLP-1 in the life and death of pancreatic beta cells, Horm Metab Res, 36, 804-810.

[31] K. A. S. D. Preissner, (1998) Role of vitrGonectin and its receptors in haemostasis and vascular remodeling, Thromb Res, 89, 1-21.

[32] R. P. Rafaeloff, G. L. Barlow, S. W. Qin, X. F. Yan, B. Rosenberg, L. Duguid, and A. I. Vinik, (1997) Cloning and sequencing of the pancreatic islet neogenesis associated protein (INGAP) gene and its expression in islet neogenesis in hamsters, J Clin Invest, 99, 2100-2109.

[33] L. Rosenberg, (1995) In vivo cell transformation: neogenesis of beta cells from pancreatic ductal cells, Cell Transplant, 4, 371-383.

[34] L. Rosenberg, R. Rafaeloff, , D. Kakugawa, Y. Pittenger, A. I. G. Vinik, and W. P. Duguid, (1996) Induction of islet cell differentiation and new islet formation in the hamster-further support for a ductular origin, Pancreas, 13, 38-46.

[35] E. A. P. Ruoslahti, (1987) New perspectives in cell adhesion: RGD and integrins, Science, 238, 491-497.

[36] K. A. Y. F. Silver, (2001) ARIP cells as a model for pancreatic beta cell growth and development, Pancreas, 22, 141-147.

[37] S. E. Sipione, A. Lyon, J. G. Korbutt, and R. C. Bleackley, (2004) Insulin expressing cells from differentiated embryonic stem cells are not beta cells, Diabetologia.

[38] A. N. H. Suzuki and H. Taniguchi, (2003) Glucagon-like peptide 1 (1-37) converts intestinal epithelial cells into insulin-producing cells, Proc Natl Acad Sci U S A, 100, 5034-5039.

[39] G. L. Teitelman and D. J. Reis, (1987) Differentiation of prospective mouse pancreatic islet cells during development in vitro and during regeneration, Dev Biol, 120, 425-433.

[40] K. Terazono, H. Yamamoto, S. Takasawa, K. Shiga, Y. Yonemura, Y. Tochino, and H. Okamoto, (1988) A novel gene activated in regenerating islets, J Biol Chem, 263, 2111-2114.

[41] B. Thorens, (1992) Expression cloning of the pancreatic beta cell receptor for the gluco-incretin hormone glucagon-like peptide 1, Proc Natl Acad Sci U S A, 89, 8641-8645.

[42] B. E. A. O. Tuch, (1990) Maturation of insulinogenic response to glucose in human fetal pancreas with retinoic acid, Horm Metab Res Suppl, 25, 233-238.

[43] T. R. Y. Ulich, E. S. Cardiff, R. Yin, S. Bikhazi, N. Biltz, R. Morris, and G. F. Pierce, (1994) Keratinocyte growth factor is a growth factor for mammary epithelium in vivo: The mammary epithelium of lactating rats is resistant to the proliferative action of keratinocyte growth factor, Am J Pathol, 144, 862-868.

[44] R. N. K. Wang, and L. Bouwens, (1995) Ductto islet-cell differentiation and islet growth in the pancreas of duct-ligated adult rats, Diabetologia, 38, 1405-1411.

[45] E. S. Y. Yi, S. Harclerode, D. L. Bedoya, A. Bikhazi, N. B. Housley, R. M. Aukerman, S. L.Morris, C. F. Pierce, and T. R. Ulich, (1994) Keratinocyte growth factor induces pancreatic ductal epithelial proliferation, Am J Pathol, 145, 80-85.

[46] M. E. C. Zenilman and T. H. Magnuson, (1998) Effect of reg protein on rat pancreatic ductal cells, Pancreas, 17, $256-261$.

[47] J. W. Zhou, X. Pineyro, and J. M. Egan, (1999) Glucagon-like peptide 1 and exendin-4 convert pancreatic AR42J cells into glucagon and insulin-producing cells, Diabetes, 48, 2358-2366. 